\title{
BMJ Open Quality Multidisciplinary approach to maximise continuity in an academic internal medicine resident clinic
}

\author{
Benjamin Quick (D) , Ethan Alexander, Bethany Ramm, Wallace Rachford, \\ Janelle Quinlan, Jane Broxterman
}

To cite: Quick B, Alexander E, Ramm B, et al. Multidisciplinary approach to maximise continuity in an academic internal medicine resident clinic. BMJ Open Quality 2020;9:e000841. doi:10.1136/ bmjoq-2019-000841

Received 27 September 2019 Revised 9 March 2020 Accepted 7 April 2020

\section{Check for updates}

(c) Author(s) (or their employer(s)) 2020. Re-use permitted under CC BY-NC. No commercial re-use. See rights and permissions. Published by BMJ.

Internal Medicine, The University of Kansas Health System, Kansas City, Kansas, USA

Correspondence to Dr Benjamin Quick; bquick2@kumc.edu

\section{INTRODUCTION}

Ensuring patient-physician continuity in an academic internal medicine resident clinic is essential in providing a longitudinal clinic experience as required by the Accreditation Council for Graduate Medical Education(ACGME). ${ }^{1}$ Efforts to improve continuity in longitudinal clinics are important to patients and physicians and improve patient outcomes. $^{2}$ Concern for declining patient continuity identified by subjective patient and resident complaints prompted investigating enterprise metrics to better understand continuity within resident clinics. These metrics, as well as ACGME requirements for longitudinal continuity clinic, drove improvement efforts to increase continuity. Our aim was to increase patient continuity in all resident clinics to $\geq 75 \%$ in 4 months.

\section{METHODS}

The 69 categorical residents and 10 internal medicine-psychiatry residents at The University of Kansas Internal Medicine Residency Programme rotate on a $3+1$ week block scheduling system for inpatient and ambulatory care. During their ambulatory week, 18-20 residents have four half-days dedicated to seeing patients in their longitudinal clinic. To improve patient continuity, a multidisciplinary team formulated a stepwise, monitored, series of schedule template changes implemented in two Plan-Do-Study-Act (PDSA) cycles (table 1).

The multidisciplinary team included programme leadership, practice manager, chief residents, residents, scheduling supervisor and support operations manager. PDSA 1 restructured all resident templates to remove unscheduled NEW patient timeslots for 2.75 months. PDSA 2 was a multipronged approach in which NEW slots were returned based on enterprise dashboard access metrics.
Patient continuity was defined as the percentage of clinic visits a patient completes with their assigned resident physician over a defined time period. Continuity reports were generated monthly for 5 months starting 1 month prior to any interventions to establish baseline continuity. The number of days between a patient's request for a return appointment and the third next available appointment, or 'time to third return', was tracked weekly for each resident and used to adjust the number of NEW patient slots as outlined in table 1 . Using time to third return, instead of next return, accounted for cancellations that would falsely elevate a resident's availability.

The study was conducted as a quality improvement project and was exempt from institutional review board review by The University of Kansas Medical Center Human Subjects Committee. Patients and the public were not involved in the design or implementation of this project.

\section{RESULTS}

Preintervention patient continuity was $69.7 \%$. Two and three-quarter months following PDSA cycle 1, continuity decreased to $68.7 \%$. One month following PDSA cycle 2 effect, which was the end of our 4-month aim, resident continuity increased to $77.9 \%$ (figure 1). One year following our intervention, continuity was $74.5 \%$. The mean resident time to third return for the month prior to any interventions was 64.4 days. Following interventions, the mean decreased to 45.5 days during the final week of study.

\section{DISCUSSION}

Increasing patient continuity to $\geq 75 \%$ in a resident primary care clinic was able to be achieved by utilising a multidisciplinary team to implement a series of schedule template 


\begin{tabular}{ll}
\hline Table 1 & PDSA cycle interventions \\
\hline PDSA & Intervention \\
\hline 1 & 1a Replace unscheduled NEW slots with RET \\
& slots \\
& 2a Replace 6 of 8 NEW slots per week with \\
& HFU/UC/PHY/RET \\
& 2b Number of NEW slots per week based on \\
& resident's time to third RET \\
& $\geq 90$ days=no NEW \\
& 45-89 days=1 NEW \\
& $\leq 45$ days=2 NEW \\
& 2c Change all slots to RET for residents with \\
& only one clinic in a 4-week timeframe
\end{tabular}

HFU, hospital follow-up; PHY, physical; RET, return; UC, urgent care.

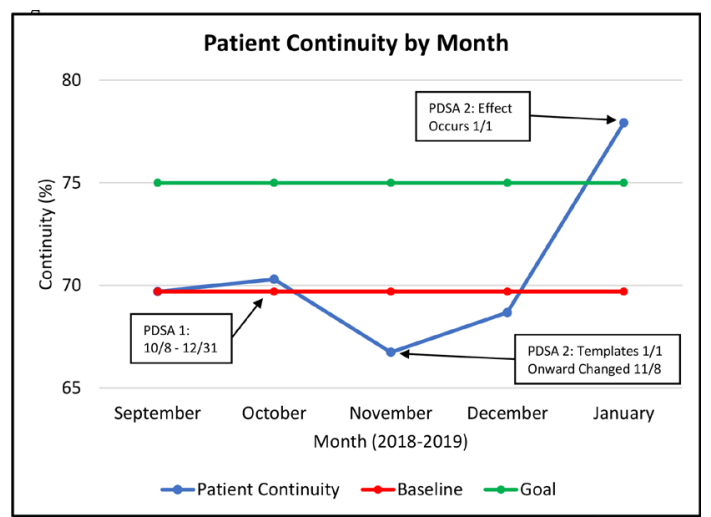

Figure 1 Effect of PDSA cycles on patient continuity by month.

changes. A high ratio of NEW to RET slots and intermittent resident availability created by $\mathrm{x}+\mathrm{y}$ scheduling were key barriers to improve continuity. The effectiveness of the interventions is likely due to increasing patient access to their resident physician by decreasing resident time to third return with the graded removal of NEW patient slots. Because continuity remained nearly $\geq 75 \%, 1$ year following project completion, it suggests the interventions are self-sustainable and not affected by changes in resident turnover.

PDSA cycle 1 did not increase continuity, likely because the number of scheduled NEW slots was already high and these appointments were not cancelled. The decline in continuity following PDSA cycle 1 is thought due to a seasonal increase of acute care visits with patients forgoing continuity for quicker access.

With a national trend towards $\mathrm{x}+\mathrm{y}$ block scheduling in residency programmes, ${ }^{3}$ the external validity of this study is strong and could be reproducible in similarly structured programmes. This study intervention is especially important when several studies showed the opposite-that patient continuity decreased with $x+y$ block scheduling. ${ }^{45}$ While the aim of this study was met, the 4-month intervention period cannot account for seasonal trends that may affect patient continuity. Other limitations include not being able to extrapolate results to the traditional half-day clinic per week model and not knowing the intervention's impact on physician continuity, no-show rate, cancellation rate, slot utilisation and time to third new appointment. Future studies are needed to evaluate these metrics.

Contributors BQ planned the study, analysed data and wrote the manuscript. EA assisted with literature review and manuscript editing. BR and JQ planned and implemented the study. WR abstracted data. JB planned and supervised the study, analysed data and edited manuscript.

Funding The authors have not declared a specific grant for this research from any funding agency in the public, commercial or not-for-profit sectors.

Competing interests None declared.

Patient and public involvement Patients and/or the public were not involved in the design, or conduct, or reporting or dissemination plans of this research.

Patient consent for publication Not required.

Ethics approval The study was conducted as a quality improvement project and was exempt from IRB review by the University of Kansas Medical Center Human Subjects Committee.

Provenance and peer review Not commissioned; externally peer reviewed.

Data availability statement All data relevant to the study are included in the article.

Open access This is an open access article distributed in accordance with the Creative Commons Attribution Non Commercial (CC BY-NC 4.0) license, which permits others to distribute, remix, adapt, build upon this work non-commercially, and license their derivative works on different terms, provided the original work is properly cited, appropriate credit is given, any changes made indicated, and the use is non-commercial. See: http://creativecommons.org/licenses/by-nc/4.0/.

ORCID iD

Benjamin Quick http://orcid.org/0000-0003-0185-1838

\section{REFERENCES}

1 Specialty and Subspecialty Program Eligibility Requirements. Accreditation Council for graduate medical education. Available: https://www.acgme.org/Portals/O/PFAssets/ProgramRequirements/ 140_InternalMedicine_2019_TCC.pdf?ver=2019-06-25-100840-923 [Accessed 26 Aug 2019].

2 van Walraven C, Oake N, Jennings A, et al. The association between continuity of care and outcomes: a systematic and critical review. $J$ Eval Clin Pract 2010;16:947-56.

3 Bowen JL, Hirsh D, Aagaard E, et al. Advancing educational continuity in primary care residencies: an opportunity for patient-centered medical homes. Acad Med 2015;90:587-93.

4 Wieland ML, Halvorsen AJ, Chaudhry R, et al. An evaluation of internal medicine residency continuity clinic redesign to a 50/50 outpatientinpatient model. J Gen Intern Med 2013;28:1014-9.

5 Heist K, Guese M, Nikels M, et al. Impact of $4+1$ block scheduling on patient care continuity in resident clinic. $J$ Gen Intern Med 2014;29:1195-9. 